\title{
The Relationship between Sitting Posture and Musculoskeletal Pain in Boy Elementary School Students
}

\author{
Saeed Ilbeigi ${ }^{1 *}$, Aboozar Kabootari², Mohamadesmaiel Afzalpour ${ }^{3}$, Hossein Farzaneh ${ }^{2}$
}

1. Associte Profesor, Sport Biomechanics Department, Faculty of Sport Sciences, University of Birjand, Birjand, Iran

2. MSc, Sport Sciences Department, Faculty of Sport Sciences, University of Birjand, Birjand, Iran

3. Professor, Exerscie Physiology Department, Faculty of Sport Sciences, University of Birjand, Birjand, Iran

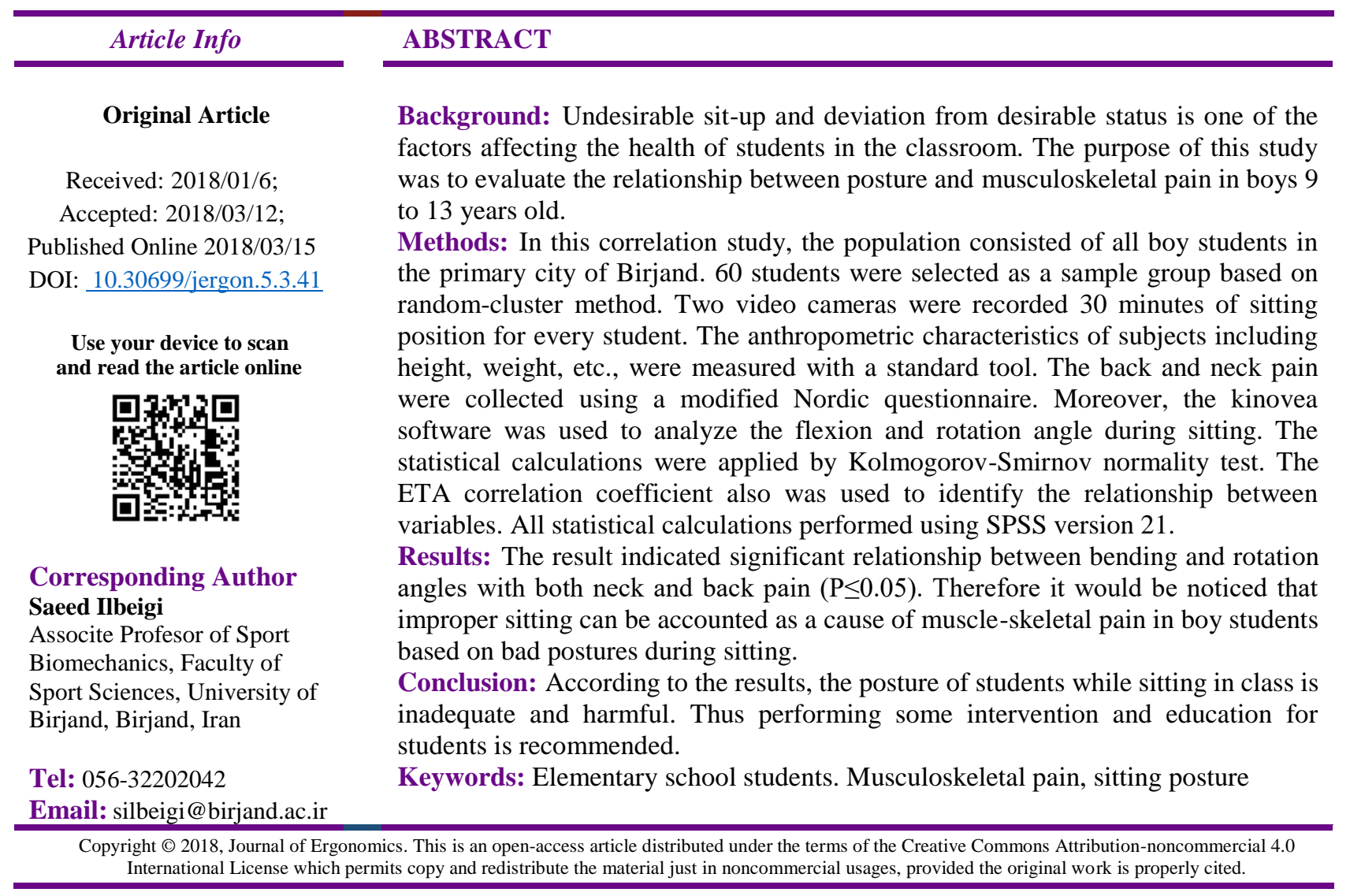

How to Cite This Article:

Ilbeigi S, Kabootari A, Afzalpour M, Farzaneh H. The Relationship between Sitting Posture and Musculoskeletal Pain in Boy Elementary School Students. J Ergon. 2018; 5 (3) :41-49 
مجله اركونومى - . IVMD-199 - سال ه، شماره r، ياييز

\section{مقالهُ يزوهشى}

ارتباط بين وضعيت نشستن در كلاس درس و درد هاى اسكلتى - عضلانى دانش آموزان پسر مقطع ابتدايى مغو

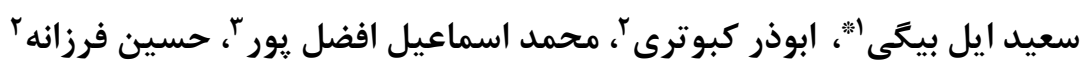

$$
\begin{aligned}
& \text { I. دانشيار، كروه بيومكانيك ورزشى، دانشكاه بيرجند، بير جند، ايران }
\end{aligned}
$$

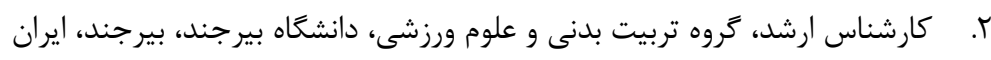

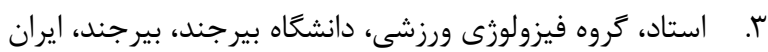

\begin{tabular}{|c|c|}
\hline خلاصه & اطلاعات مقاله \\
\hline & 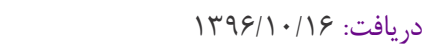 \\
\hline زمينه و هدف: وضعيت نامطلوب نشستن و انحراف از وضعيت مطلوب قامتى يكى از عوامل مؤثر در ميزان & 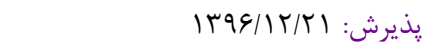 \\
\hline سلامت دانشآموزان در كلاس است. لذا هدف از اين يروهش، بررسى ارتباط بين وضعيت نشستن در & 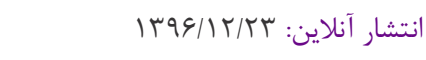 \\
\hline كلاس درس و دردهاى اسكلتى - عضلانى دانش آموزان پسر مقطع ابتدايى بود. & \\
\hline روش كار: در اين يروهشي همبستخَى، تعداد •و نفر از دانشآموزان يسر ابتدايى شهرستان بيرجند بهصورت & 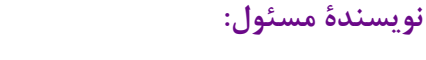 \\
\hline تصادفى - خوشه اى به عنوان نمونه آمارى انتخاب شده اند و با استفاده از دو دوربين فيلهبردارى وضعيت & سعيد ايل بيكى \\
\hline نشستن هر دانش آموز فيلمبردارى شد. سيس وضعيتهاى مورد نظر استخراج و با استفاده از نرمافزار & دانشيار، تروه بيومكانيك ورزشى، دانشگاه \\
\hline تحليل حركت كينوا، تجزيهوتحليل شدند. همجنين، جهت اندازهيرى ميزان شيوع درد از يرسشنامه & بيرجند، بيرجند، ايران \\
\hline استاندارد نورديك استفاده شد. كليه محاسبات آمارى با استفاده از نرمافزار SPSS نسخه ال در سطح & 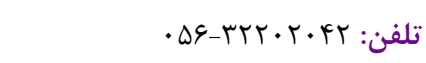 \\
\hline 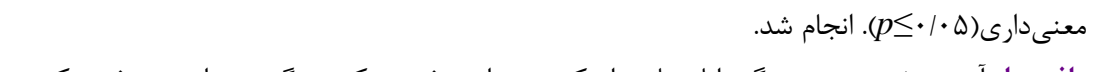 & 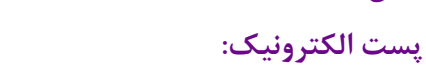 \\
\hline يافتهها: آزمون ضريب همبستكى اتا نشان داد كه بين زاويه خمش كمر و كردن، زاويه جرخش كمر و & silbeigi@birjand.ac.ir \\
\hline كردن و درد اسكلتى عضلانى كمر و كردن ارتباط معنى دارى وجود دارد (ه •|•>p). همجنين، شيوع درد & راي, دانلود اين مقاله، \\
\hline 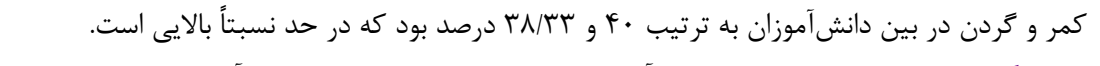 & كد زير را با موبايل خود ماتسا \\
\hline نتيجه گيرى: وضعيت نشستن اكثر دانشآموزان در كلاسهاى درس نامطلوب و آسيبزا است. بنابراين، & اسكن كنيد. \\
\hline انجام مداخلات اصلاحى و آموزش وضعيت صحيح نشستن در بين دانشآموزان مقاطع ابتدايى توصيه & 口隹和回 \\
\hline كليدوازهها: وضعيت نشستن، كلاس درس، دردهاى اسكلتى - عضلانى، دانش آموزان ابتدايى & 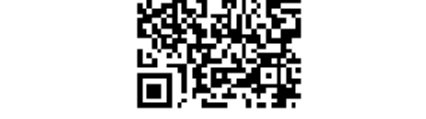 \\
\hline
\end{tabular}

مقدمه

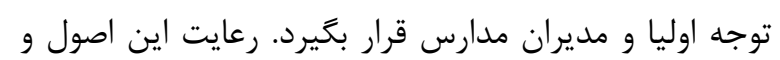

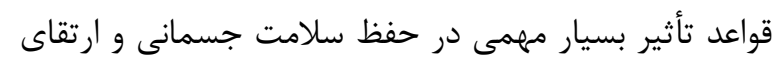

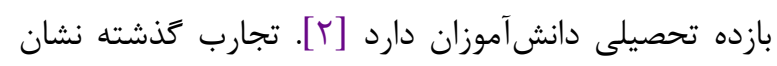

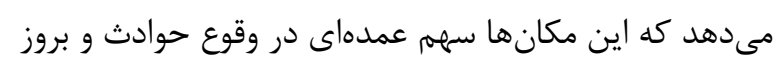
بيمارىها در كشورهاى درحال توسعه دارند [بَ].

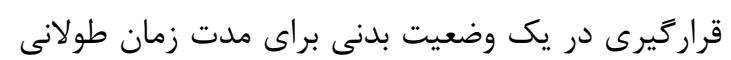

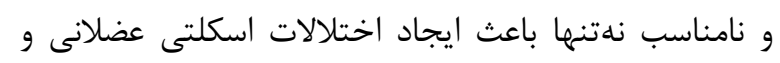

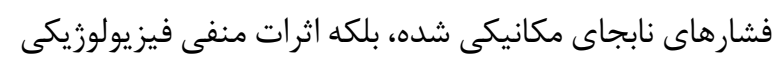

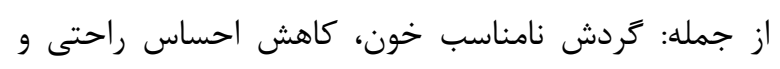

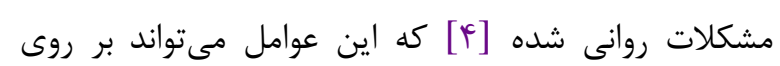

وضعيت نشستن يكى از عوامل مؤثر در ايجاد اختلالات

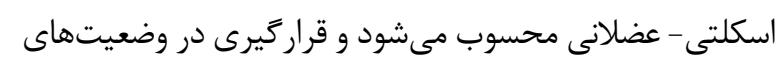

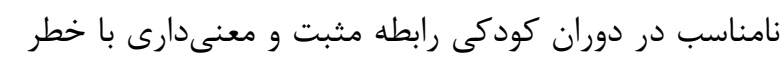

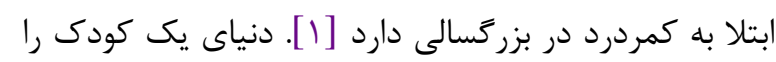

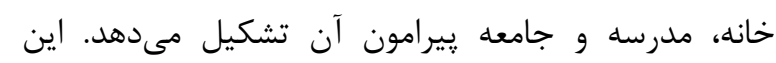

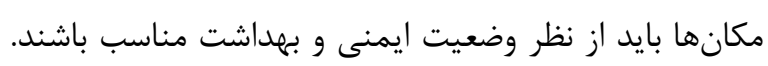
براى رسيدن به اين هدف بايد عوامل مؤثر در اين زمينه كه ائه

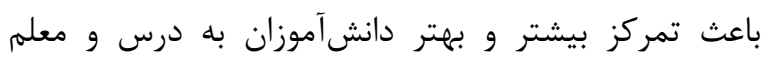

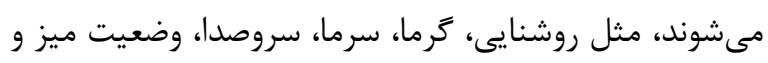

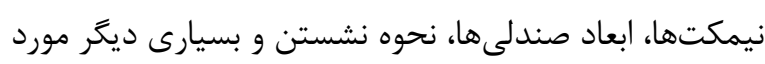


حاكى از آن است كه، نحوه نشستن و قراخيرى نامناسب دانشآموزان در كلاس درس، جزء عوامل فيزيكى مؤثر در خطر

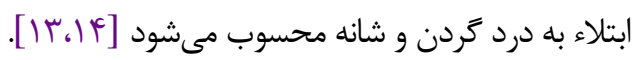

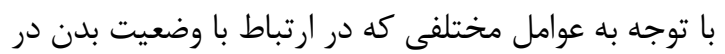

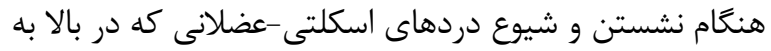
آن اشاره شد و همجنين بررسى حالتهاى مختلف نشستن در

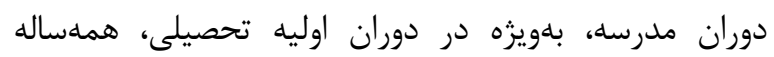
هزينههاى زيادى صرف درمان اين ناهنجارىها مىشود؛ بنابراين، بهتر است همه متصديان تربيتبدنى و ورزش، بلهويزه

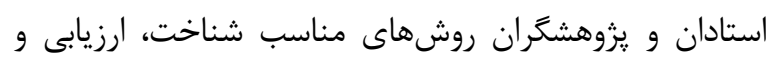
بيشخيرى از بروز و شيوع ناهنجارىها را شناسايى و در جهت رفع و اصلاح آن كوشش كنند [ه]. از طرف ديخر، ازآنجايى كه بهترين سن براى ييشخيرى و اصلاح ناهنجارىهاى جسمانى

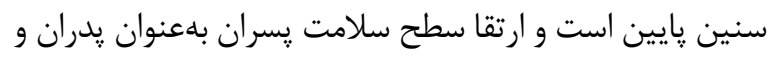

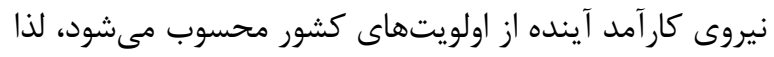
انجام جنين يزروهشهايى باهدف شناسايى، اصلاح و جلوكيرى

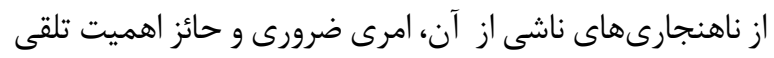
شده و هدف از اين يزوهش نيز، بررسى رفتار وضعيتى كودكان

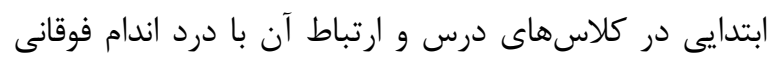
بلهويزه يشت و گردن دانش آموزان بود.

\section{روش كار}

تحقيق حاضر از نوع توصيفى (غير آزمايشى) همبستخى بود. جامعه آمارى اين تحقيق، شامل تعداد · . هو دانش آموز

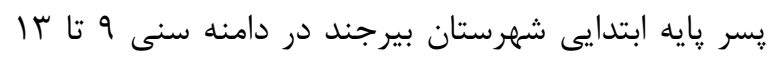

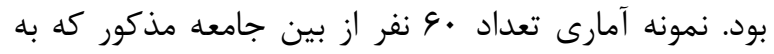
روش نمونه منظور محققين، با توجه به وضعيت توزيع مدارس در مناطق

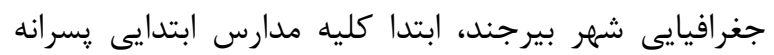
بيرجند را به ه ناحيه تقسيم كرده و سيس، از هر ناحيه، دو مدرسه بلهصورت تصادفى انتخاب شد. در نهايت، از هر مدرسه

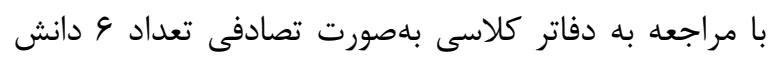

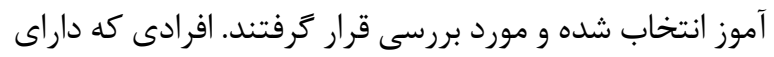
ناهنجارى يا آسيبديدگى ساختارى مادرزادى بودهاند از نمونه آمارى حذف شده و افراد ديخرى جايگزين اين دسته از افراد

مى شدند. براى جمع آورى اطلاعات، يس از اخذ مجوزهاى مربوطه از اداره كل آموزشويرورش خراسان جنوبى و اداره آموزش و

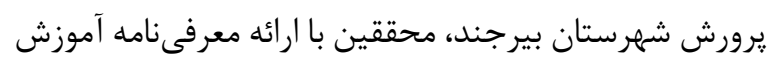

وضعيت سلامتى، تعاملات اجتماعى، ارتباط با همسالان،

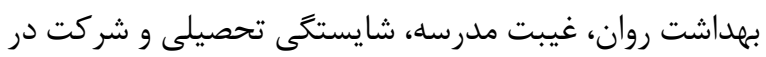

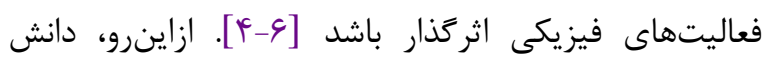

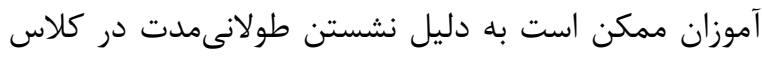
درس و وضعت بدنى نامناسب در معرض خطر ابتلا به كمردرد باشند [ه]. اكر جه شيوع درد اسكلتى - عضلانى با افزايش سن افزايش مىيابد [V،V] و تعداد زيادى از بزرگسالان دجار اين عارضه هستند، باينوجود، اولين زمان شروع اين دردها در دوران نوجوانى و كودكى گزارششده است [V،A]. در اين راستا، Caneiro كه وضعيتهاى مختلف نشستن بهطور معنىدارى بر روى وضعيت گردن، سر و فعاليت عضلانى ستون گردنى سينهاى

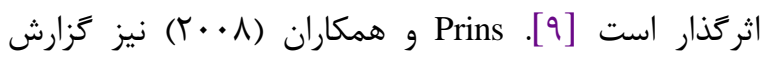
كردهاند كه نشستنهاى طولانى عامل اصلى اختلالات اسكلتى عضلانى است و ارتباط معنى دارى با عوامل روانى اجتماعى ازجمله افسردگى، ناراحتى ها و دردهاى عصبى - عضلانى دارد

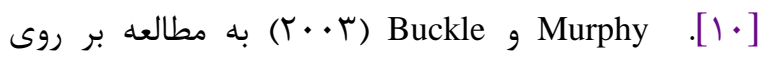
وضعيت نشستن دانشآموزان نشان دادند كه فعاليت كم در طول كلاس درس با درد يشت و گردن ارتباط معنى دارى دارد

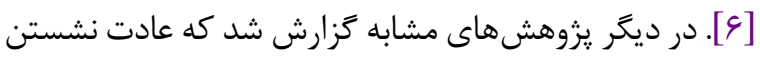

در مدارس فعال، بهتر از وضيعت ساير مدارس است [11].

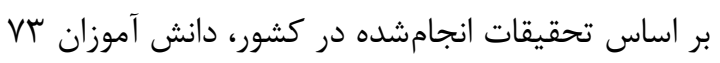
درصد از وقت خود را در مدرسه در وضعيت نشسته روى ميز و نيمكتها مى گذرانند. جهابسا تغييرات كوجكى در ارتفاع ميز و نيمكت هاى مورد استفاده دانش آموزان در مدرسه و همجنين آموزش الكوهاى نشستن صحيح مىتواند موجب حذف يا

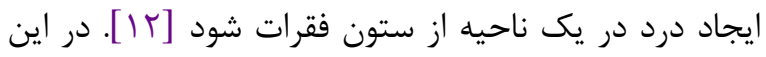
رابطه، يروهشهاى انجام شده تلاش براى از بين بردن يا

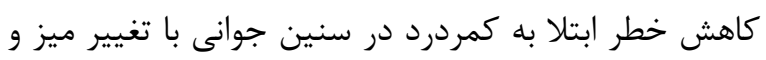

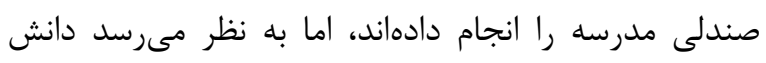

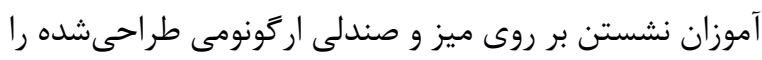

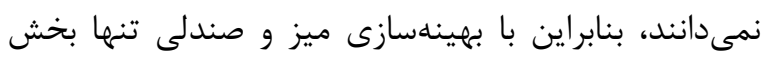

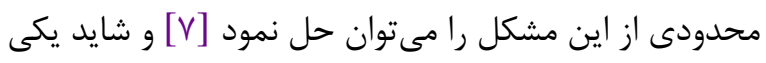
ديخر از روش هاى مؤثر در كاهش اين اختلال آموزش نشستن مناسب بر روى ميز و صندلى باشد. از طرف ديخر، نتايج

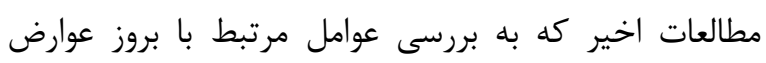
اسكلتى - عضلانى در بين دانش آموزان مدارس كشور يرداختهاند 
اين يرسشنامه اطلاعات مفيد و قابلاعتمادى در مورد علائم اختلالات عضلانى - اسكلتى فراهم مى كند كه ميى توان از اين اطلاعات جهت بررسىهاى عميقتر و يا تصميمى احيرى در زمينه اقدامهاى اصلاحى استفاده كرد [هات إن].

\section{روش تجزيهوتحليل دادهها}

يس از جمع آورى اطلاعات اوليه توسط دوربينهاى مورد

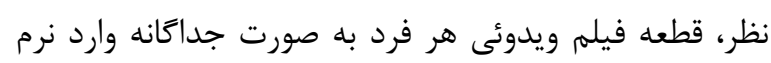

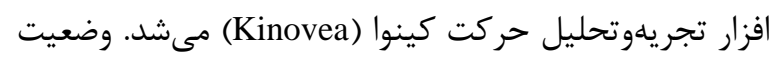
و يوسجر بدنى تكرارى دانش آموزان در سه حالت (خواندن، كوشدادن و نوشتن) آناليز و زوايه گذارى شد (شكل شماره إن).

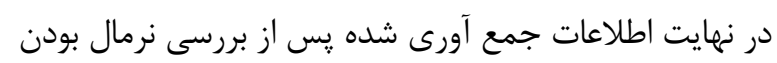

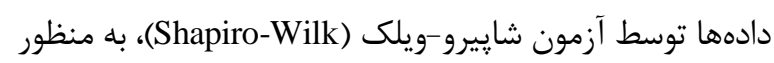
بررسى ميزان همبستخى از آزمون ضريب همبستخى اتا استفاده شد. كليه محاسبات آمارى به كمك نرمافزار SPSS نسخه

در سطح (ه • • (p) )، انجام شد.

\section{نرمافزار تحليل حركت kinovea}

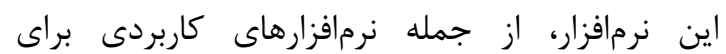
تجزيهوتحليل حركات و وضعيتهاى مختلف بدنى است كه

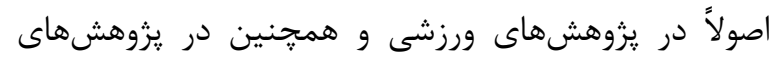

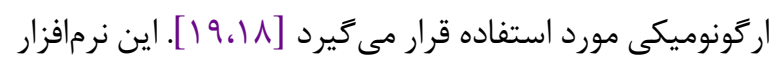
با قابليت وارد كردن قطعه فيلمهاى ويدوئى و دارا بودن ساير

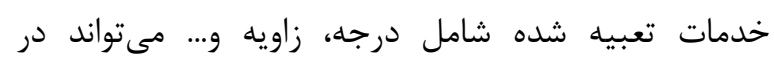
زمانهاى مشخص فيلم را تبديل بهعكس، ياوريوينت يا فيلم

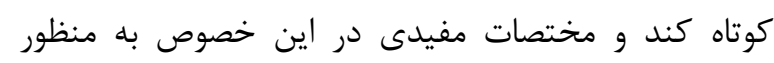
ارزيابى و برآورد زاويه داشته باشد.
و يرورش براى هماهنگگى با مديران و دبيران به مدارس مراجعه

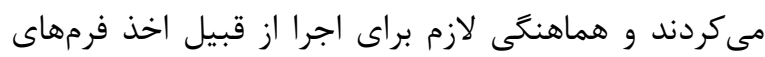
مخصوص رضايتنامه براى شركت در تحقيق در اختيار دانشآموز و والدين قرار مى گرفت. سيس در هر مدرسه، در زمانى كه دانش آموزان در كلاس حضور نداشتند، موقعيت كلاس براى جاگذارى دوربين مورد بررسى قرار گرفت و دوربين

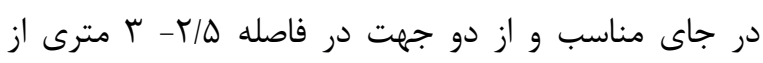

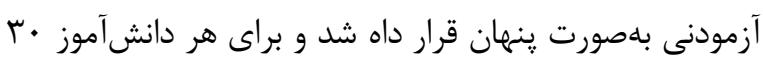

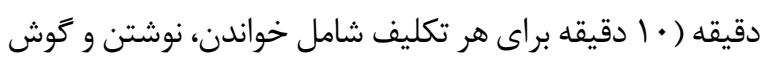

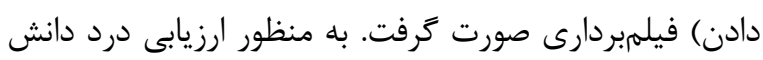

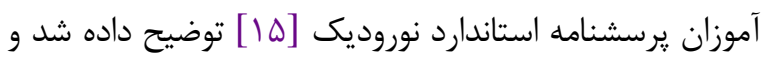
اطلاعات جمعآورى گرديد.

\section{يرسشنامه استاندارد نورديك}

اين يرسشنامه در واقع يك شيوه خودگزارشى است كه در سال I91V I Kuorinka و همكاران در انستيتو بهداشت

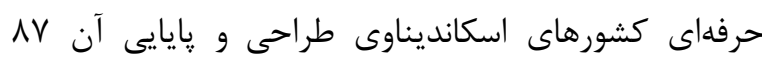

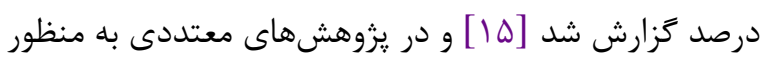
تعيين ميزان شيوع نارحتىهاى اسكلتى - عضلانى استفاده شده است [IV،|C]

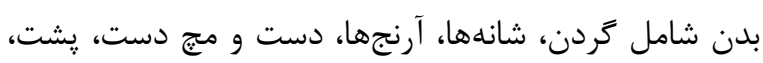

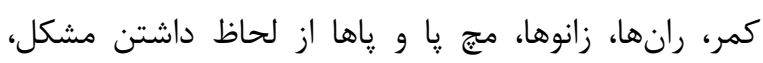
ناراحتى و اينكه اين كه ناراحتى باعث ترك كار يا ناتوانى فرد

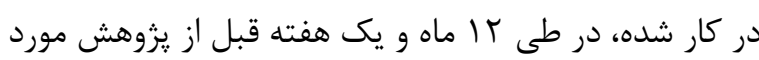
بررسى قرار مى گيرند. بهطوركلى، طراحى اين يرسشنامه دو

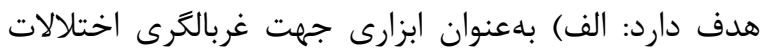

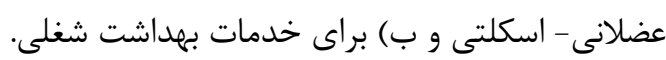

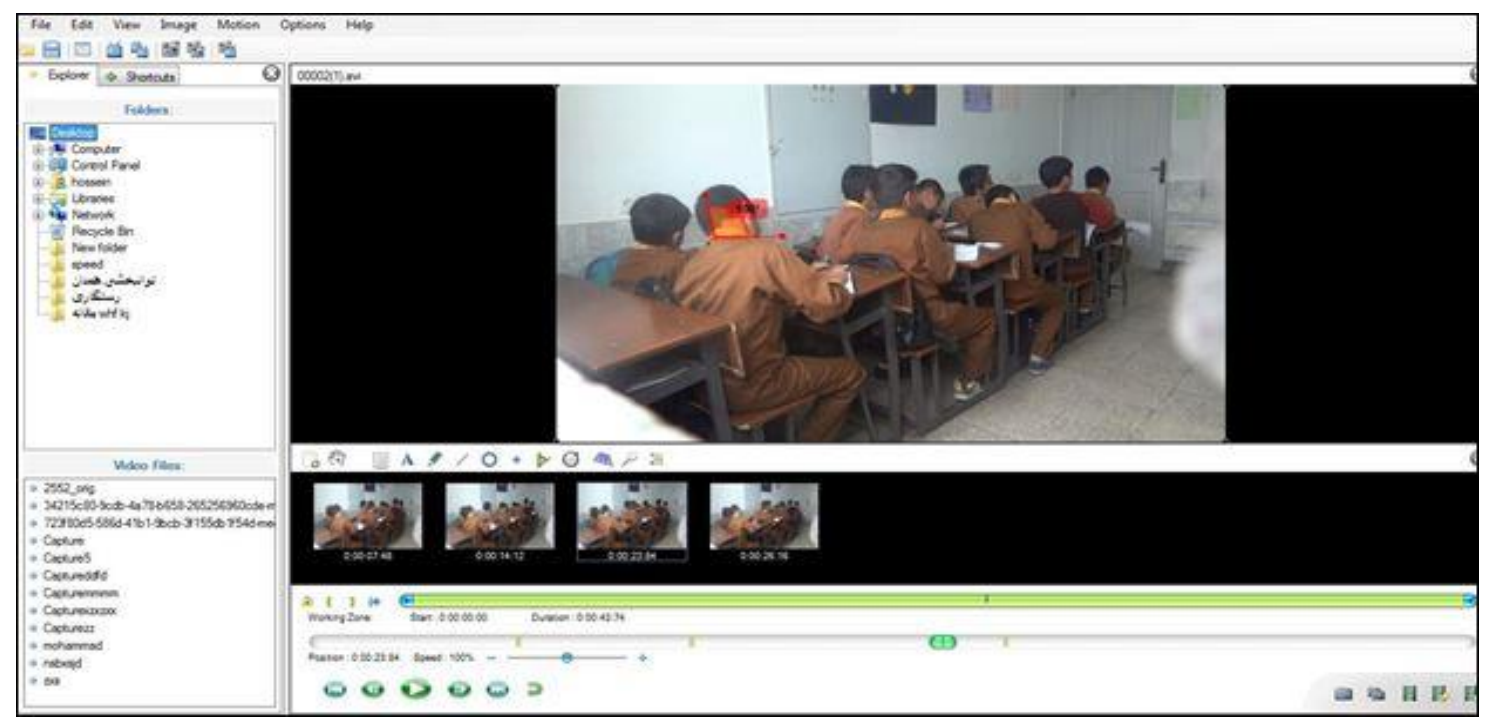



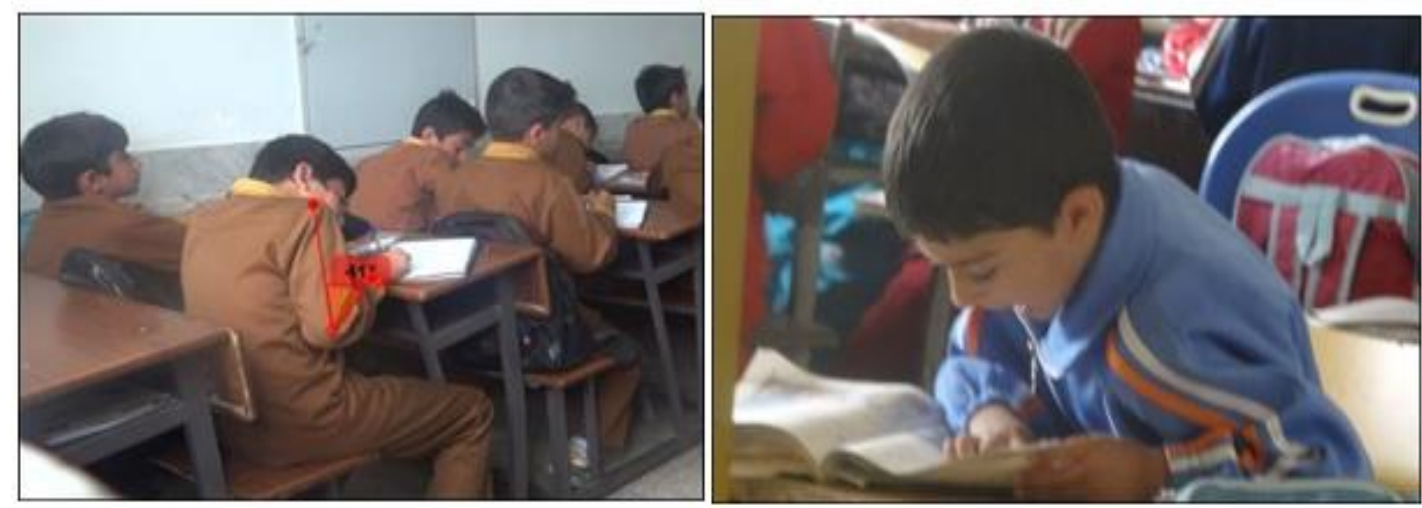

kinovea شكل ا. يوسجرهاى انتخاب شده و نماى از محيط نرم افزار

مناسبى نيست و به ترتيب بيشترين زاويه مربوط به خم بودن

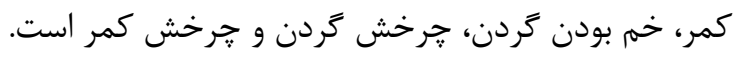

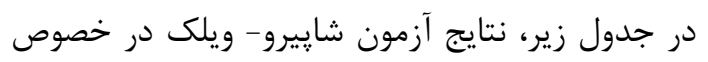

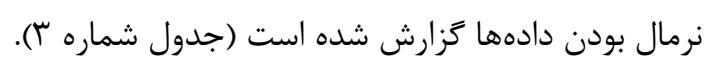

جدول شماره س. نتايج آزمون شاييرو - ويلك

\begin{tabular}{|c|c|c|}
\hline سطح معنى دارى & Z آماره Z & متغير \\
\hline$\cdot / r \cdot V$ & $1 / 911$ & קرخش كردن \\
\hline - & $1 / .90$ & خمش گردن \\
\hline$\cdot / 9 \cdot V$ & $1 / 191$ & קرخش كمر \\
\hline.$/ 1 T \Delta$ & $1 / \pi r$. & خمش كمر \\
\hline
\end{tabular}

همانطورى كه در جدول نشان داده شده است با توجه

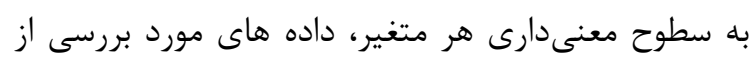

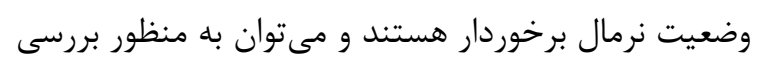

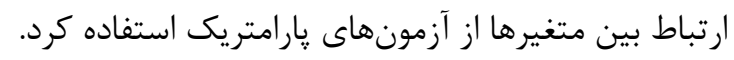

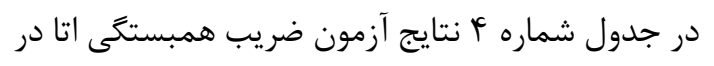
خصوص ارتباط بين متغير هاى مورد بررسى نشان داده شده أندان

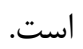

جدول شماره F. نتايج آزمون ضريب همبستغى اتا در خصوص

\begin{tabular}{|c|c|c|}
\hline دردكمر (ضريب اتا) & درد كردن (ضريب اتا) & متغير \\
\hline & $\cdot / \mathrm{V} \backslash \mathrm{A}^{*}$ & جرخش كردن \\
\hline & $\cdot|\Lambda| 9^{*}$ & خمش كردن \\
\hline . $\mid 9 \wedge Y^{*}$ & & جرخش كمر \\
\hline •/V१९ * & & خمش كمر \\
\hline
\end{tabular}

$\mathrm{P} \leq \cdot /$ • رابطه معنى دار در سطح *
يافته ها

جدول ا نشان دهنده فراوانى و درصد فروانى نسبى متغير

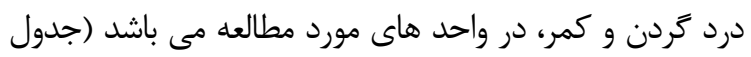

جدول ا. اطلاعات مربوط به درد كمر و حردن

\begin{tabular}{|c|c|c|}
\hline درصد & فراوانى & متغير \\
\hline r. & TF & درد كمر \\
\hline r & $r$ & درد گردن \\
\hline
\end{tabular}

با توجه به نتايج جدول فوق، ميزان شيوع درد كمر نسبت به درد گردن تفاوت قابل توجهى ندارد.

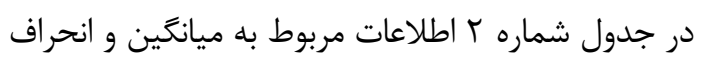

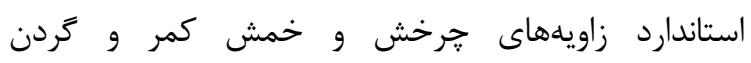
دانشآموزان در وضعيت نشسته در كلاس هاى درس ار ارئه شده

جدول شماره r. اطلاعات مربوط به زاويههاى حرخش و خمش،

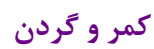

\begin{tabular}{|c|c|}
\hline ميانكَين و انحراف استاندارد & متغير \\
\hline$r \Delta / \cdot \Delta \pm \mid r / r \Lambda$ & جرخش گردن \\
\hline$r I / \cdot \Lambda \pm 1 \Lambda / r \Delta$ & خمش كردن \\
\hline$r T / / D \pm I r / A T$ & خرخش كمر \\
\hline$r \Delta / q \Gamma \pm 11 / 19$ & خمش كمر \\
\hline
\end{tabular}

نتايج جدول ب نشان دهنده اين مطلب است كه ميانكَين

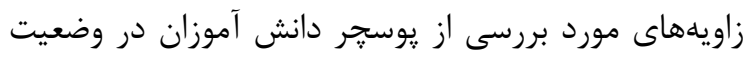




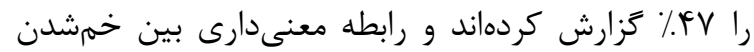

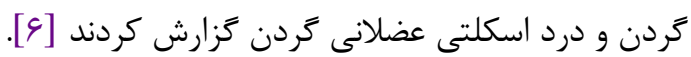

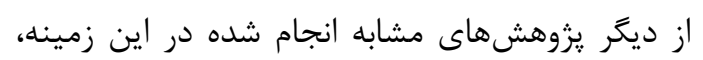

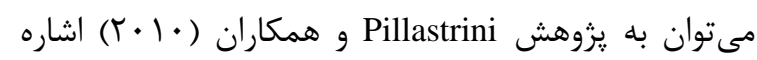

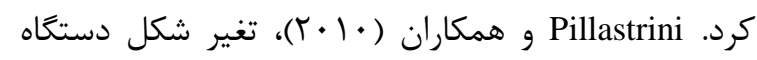

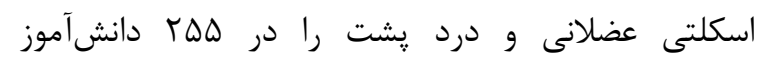

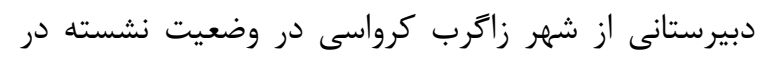

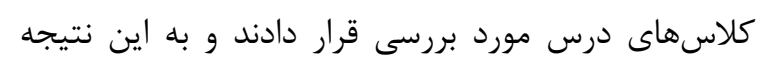

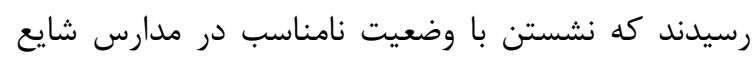

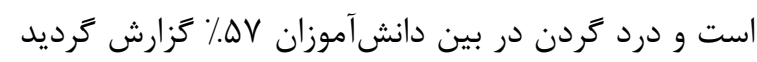

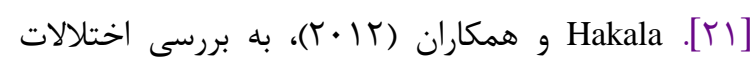

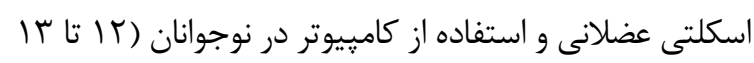

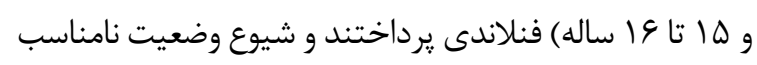

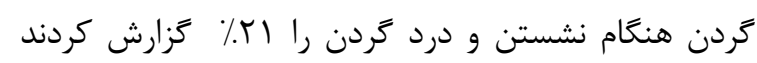

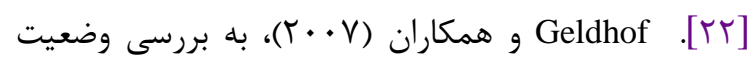

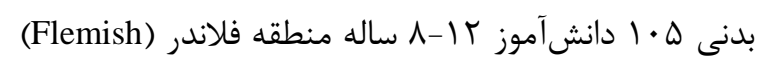

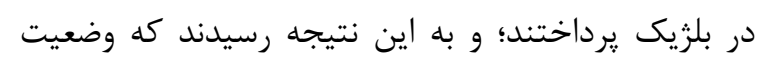

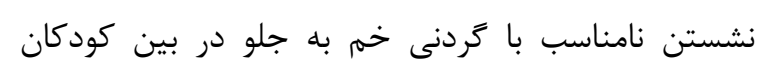

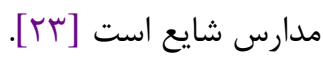

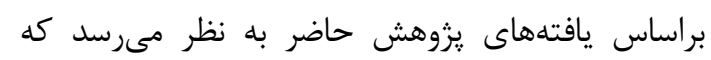

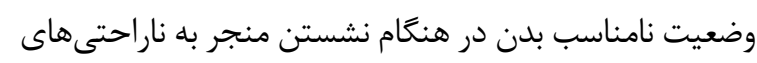

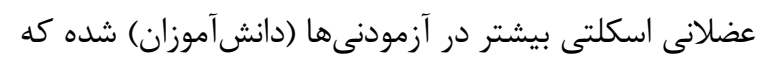

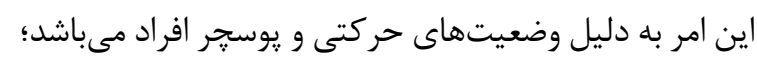

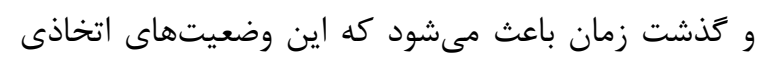

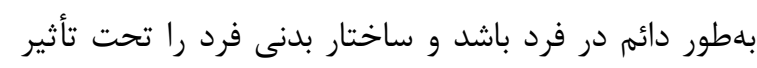

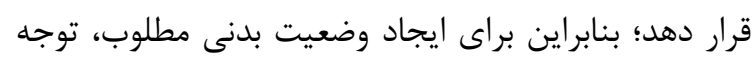

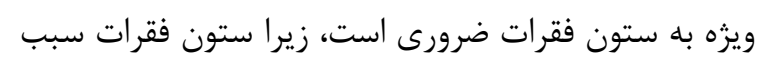

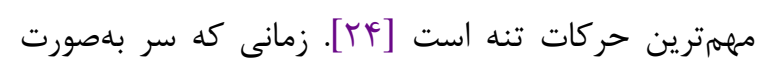

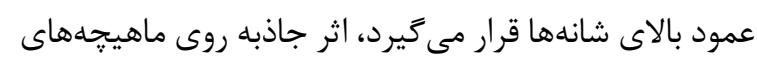

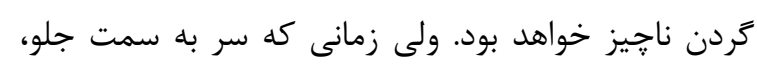

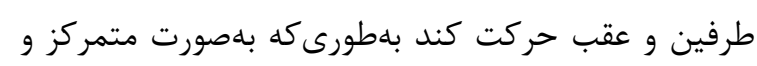

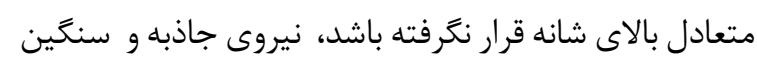

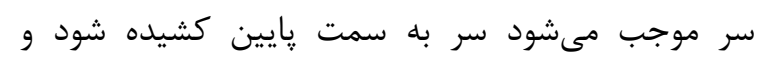

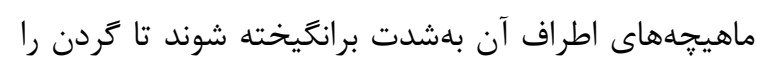

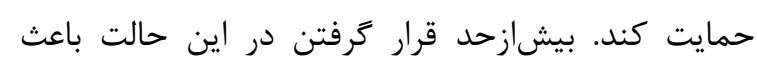
بيشازحد منقبض شدن و كشيدگى عضلات مى شعود. اين امر

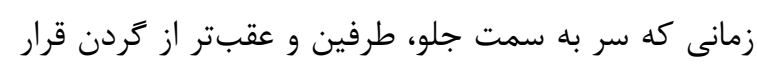

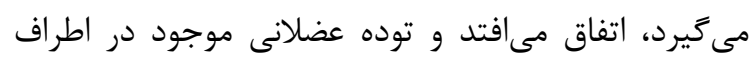

بر اساس نتايج آزمون ضريب همبستى اتا، بين جرخش كردن و خمش كردن با ميزان دردهاى اسكلتى- عضلانى إنى

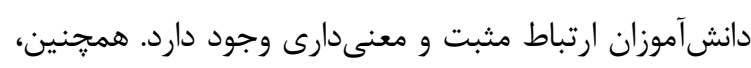

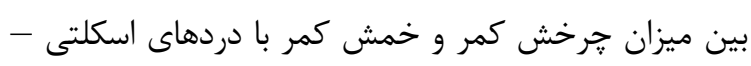

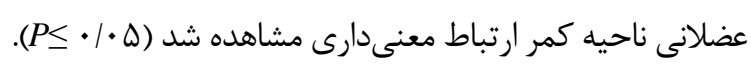

\section{بحث}

هدف از انجام اين يزوهش بررسى ارتباط بين وضعيت نشستن در كلاس درس و دردهاى اسكلتى -عضلانى دانشآموزان آنسان

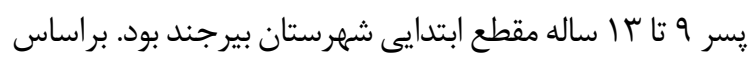

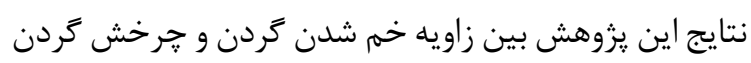

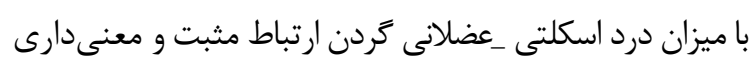

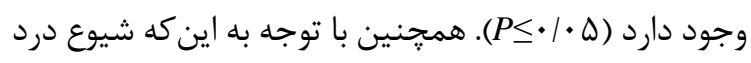

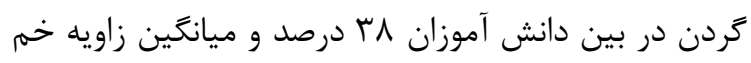

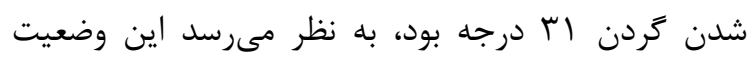

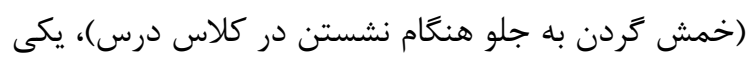

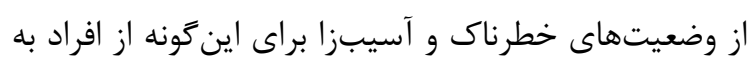

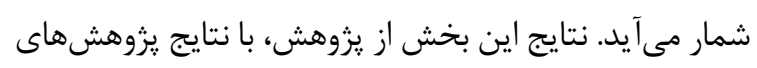
Dianat Brink Hakala

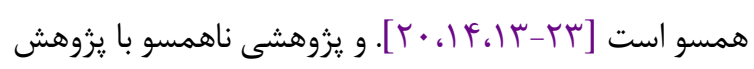

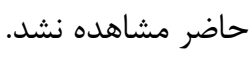
م Dianat مرتبط با بروز عوارض اسكلتى-عضلانى در بين دانشآ آموزان

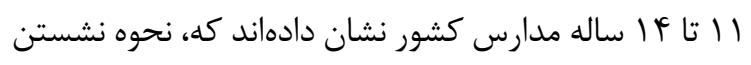

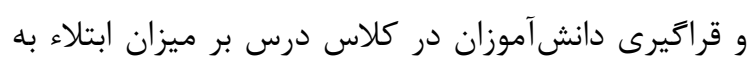

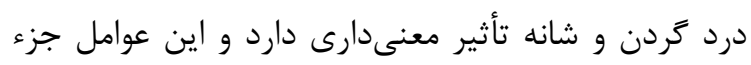

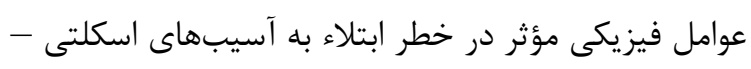

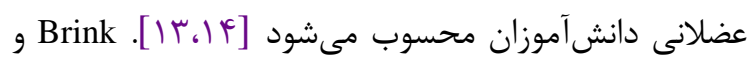

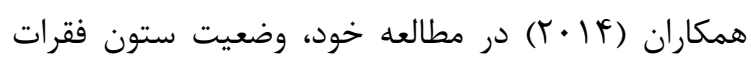

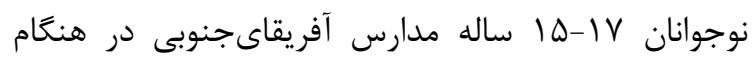

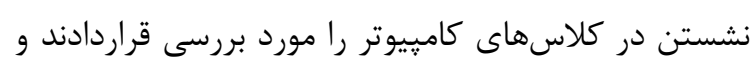

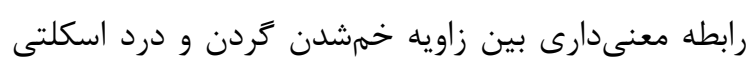

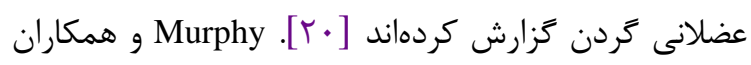

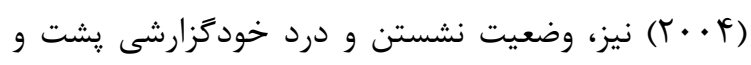

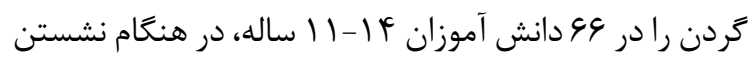

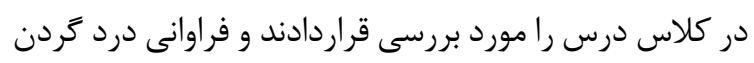


دانشآموزان ابتدايى گزارش كردند، كه با نتايج يزوهش

$$
\text { حاضر همسو است [ع]. }
$$

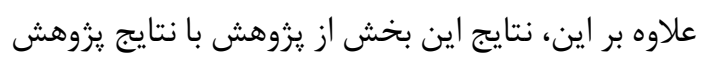
Geldhof

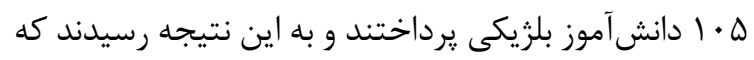

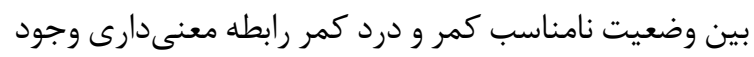

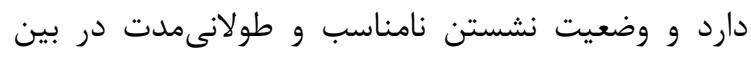
كودكان مدارس شايع است [rr]]، همخوانى دارد.

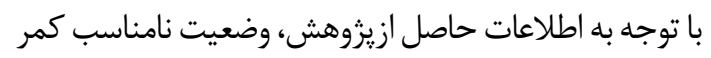
موجب بروز درد در دانشآموزان شده كه اين مسئله به خاطر إند

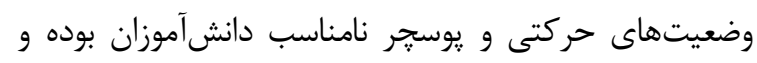

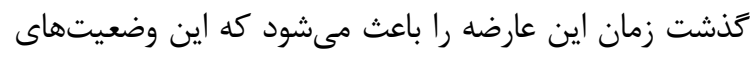

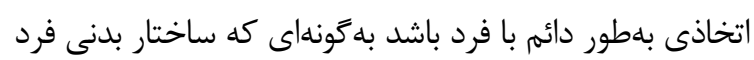

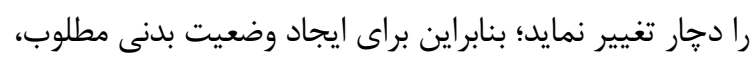

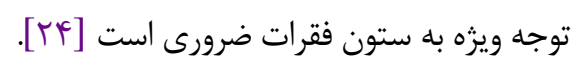

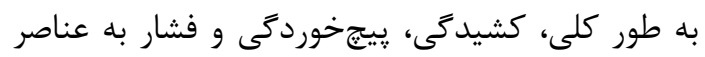

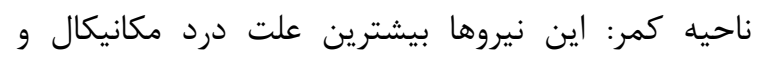

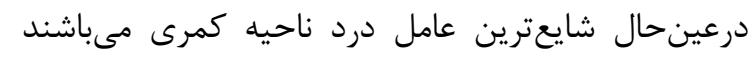

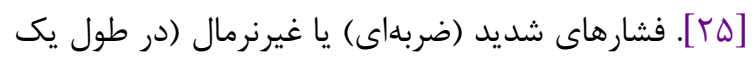

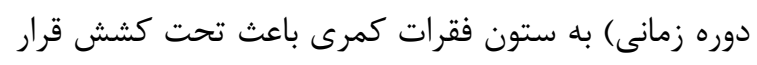

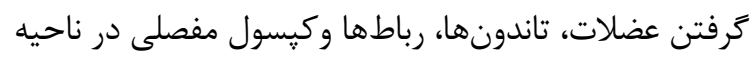

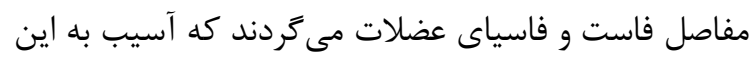

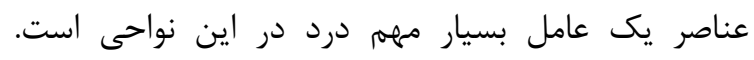

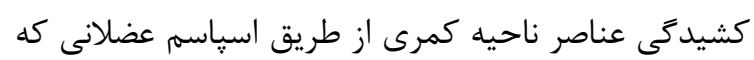

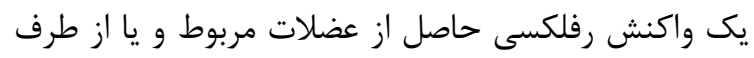

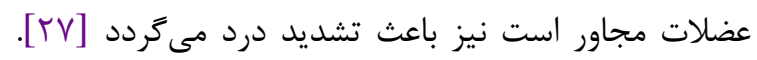

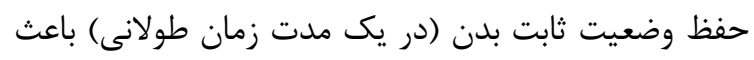

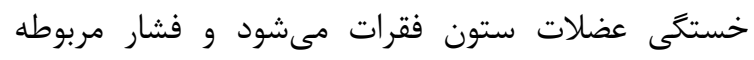

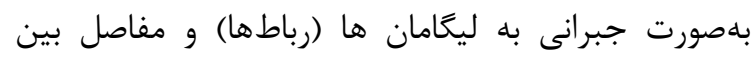

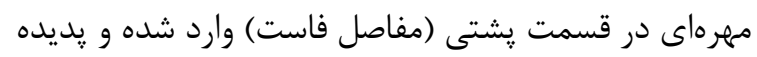
درد به دليل آسيب اين عناصر، تجمع مواد زائد ناشى از

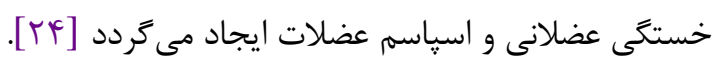

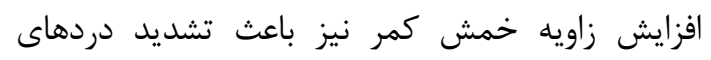

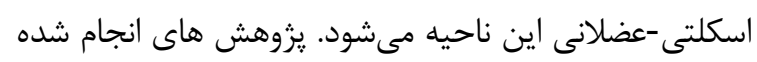

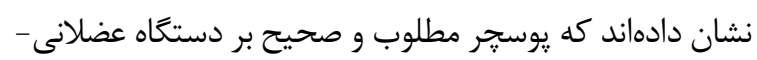

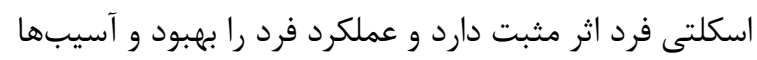

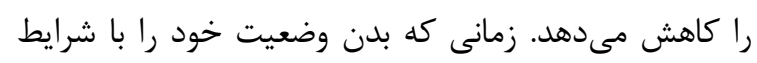
تطبيق مى دهد، امكان اين وجود دارد كه بلمرورزمان همان بدان
ستون فقرات، استوارى ستون مهرهها را تحت فشار قرار مى مهد [ro] قراركيرى بلهور مداوم دريكى از اين وضعيتها باعث فشردگى يا كشيدگى در مفاصل فاست (Facet Joint)

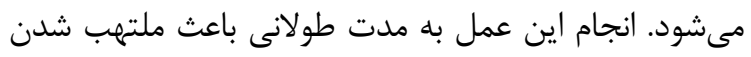

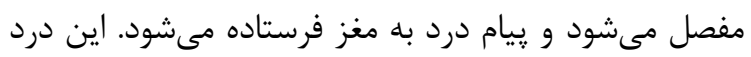

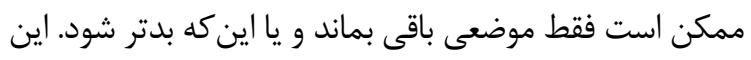

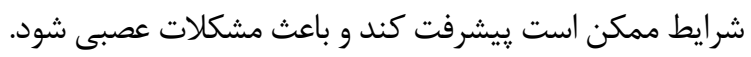

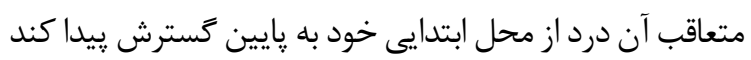

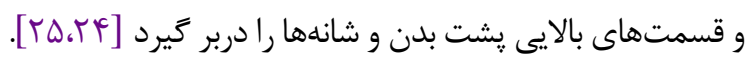

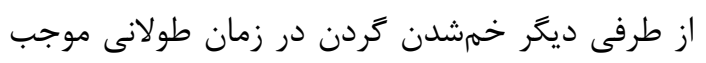

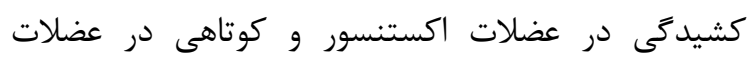

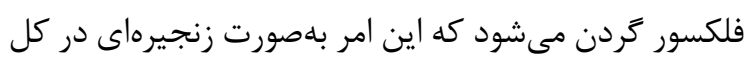

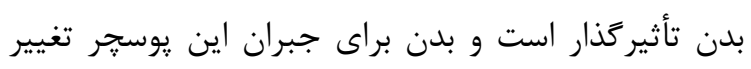

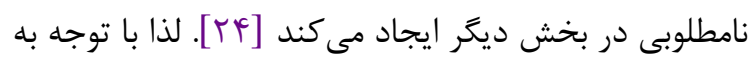

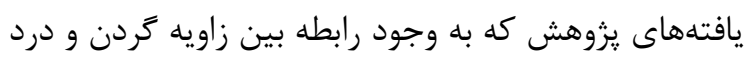

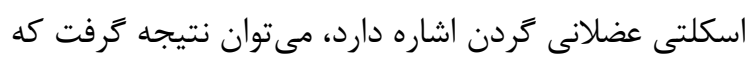

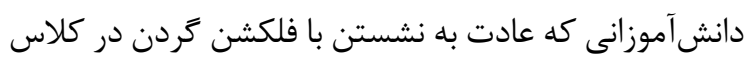

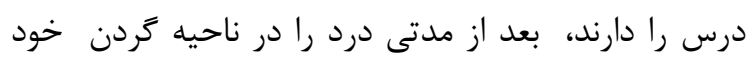

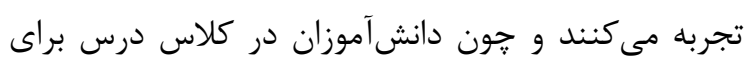

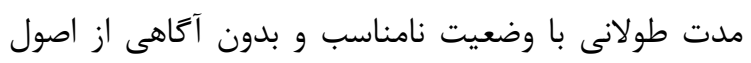
صحيح نشستن و عوارض ناشى از نشستن نامناسب آناهي ناهي

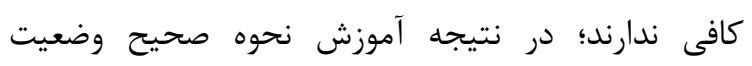

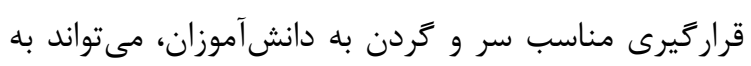
مقدار قابل توجهى از بروز دردها و عوارض نمارد ناشى از داز آن بكاهد.

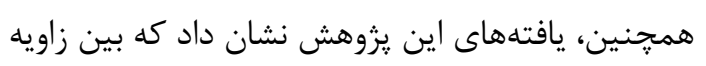
جرخش و خمش تنه با درد اسكلتى-عضلانى كمر ارتباط

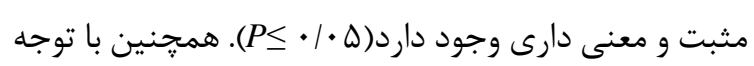

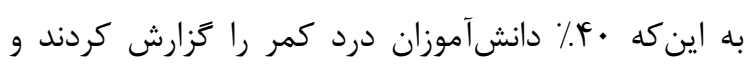

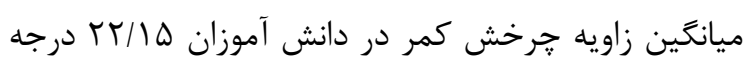

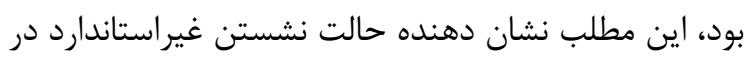

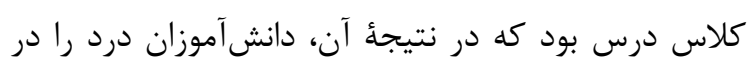

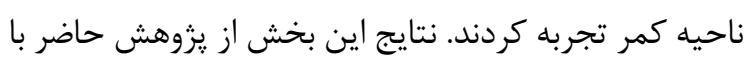

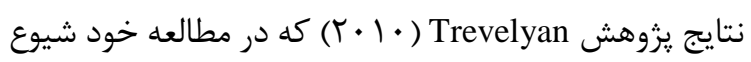
و خصوصيات درد يشت را در كودكان مدرسه نيوزيلند مورد

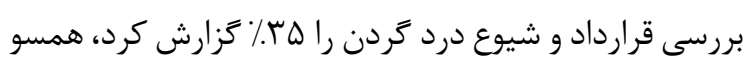

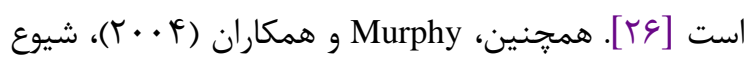
بالايى از درد كمر مرتبط با وضعيت نشستن را دران در بين 


$$
\begin{aligned}
& \text { ممكن است در صورت عدم توجه در طولانى مدت با عوارض }
\end{aligned}
$$

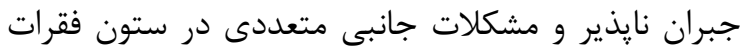

$$
\begin{aligned}
& \text { همراه شود. لذا، توصيه مىشود به منظور اصلاح وضعيت } \\
& \text { نشستن و يُيشَرى از ساير عوارض ناشى از اختلالات مرتبط } \\
& \text { با آن، آموزشهاى لازم و انجام اقدامات اصلاحى به اين دسته } \\
& \text { از دانش آموزان ارائه كردد. } \\
& \text { تقدير و تشكر }
\end{aligned}
$$

بدين وسيله از تمام كسانى كه ما را در انجام اين يزوهش

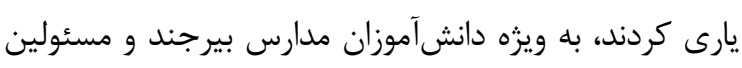

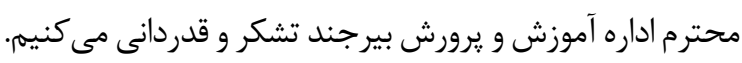

$$
\text { تعارض منافع }
$$

بين نويسندكان هيجَّونه تعارضى در منافع وجود ندارد.

\section{References}

1. Harrison DD, Harrison SO, Croft AC, Harrison DE, Troyanovich SJ. Sitting biomechanics part I: review of the literature. J Manipulative Physiol Ther. 1999 NovDec;22(9):594-609. https://doi.org/10.1016/S01614754(99)70020-5 PMID: 10626703

2. Mirzaei R, Ansari H, Khammari A, Afrouz M. Survey of relationship between ergonomic and environmental conditions of classrooms and pain sensation in students [Persian]. J Qazvin Univ Med Sci. 2010;13(4):36-41.

3. Kermani M, Farzadkia M, Yousefi Z, Ghandali R. Investigating the Environmental Health and Safety Status among Primary Schools [Persian]. Majallah-i Danishgah-i Ulum-i Pizishki-i Mazandaran. 2012;22 (95):85-9.

4. Guite JW, Logan DE, Sherry DD, Rose JB. Adolescent self-perception: associations with chronic musculoskeletal pain and functional disability. J Pain. 2007 May;8(5):379-86. https://doi.org/10.1016/ j.jpain.2006.10.006 PMID: 17275417

5. Waersted M, Hanvold TN, Veiersted KB. Computer work and musculoskeletal disorders of the neck and upper extremity: a systematic review. BMC Musculoskelet Disord. 2010 Apr;11(1):79. https://doi.org/10.1186/1471-2474-11-79 PMID:20429925

6. Murphy S, Buckle P, Stubbs D. Classroom posture and self-reported back and neck pain in schoolchildren. Appl Ergon. 2004 Mar;35(2):113-20. https://doi.org/10.1016 /j.apergo.2004.01.001 PMID:15105072

7. Brink Y, Louw QA. A systematic review of the relationship between sitting and upper quadrant musculoskeletal pain in children and adolescents. Man Ther. 2013 Aug;18(4):281-8. https://doi.org/10.1016 /j.math.2012.11.003 PMID:23298827

$$
\begin{aligned}
& \text { وضعيت ادامه يابد و سرانجام غيرقابل بر گشت باشد و در صورت } \\
& \text { ادامه اين وضعيت، فيبرهاى عضلانى و بافتهاى نرم كوتاه } \\
& \text { خواهد شد، به تعبيرى ديخر از مرحله الاستيسيتى (Elasticity) }
\end{aligned}
$$

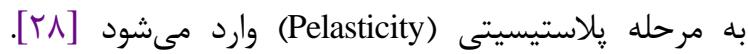

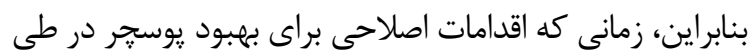

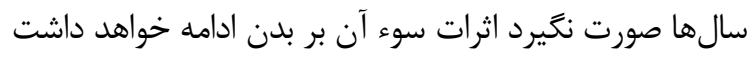

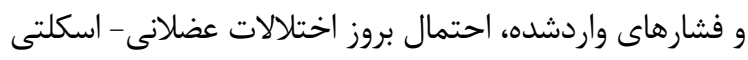

$$
\begin{aligned}
& \text { را افزايش خواهد داد [Tr] } \\
& \text { نتيجه گَيرى } \\
& \text { وضعيتهاى نامطلوب نشستن دانشآموزان در كلاس }
\end{aligned}
$$

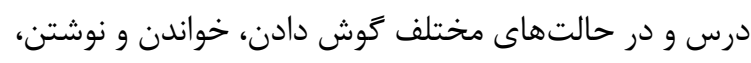

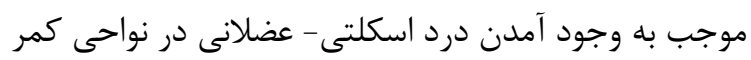

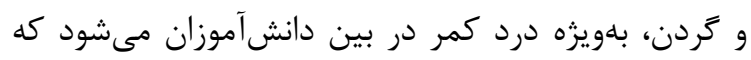

8. Perry MC, Straker LM, O'Sullivan PB, Smith AJ, Hands B. Fitness, motor competence and body composition as correlates of adolescent neck/shoulder pain: an exploratory cross-sectional study. BMC Public Health. 2008 Aug;8(1):290. https://doi.org/10.1186/1471-24588-290 PMID:18702827

9. Caneiro JP, O’Sullivan P, Burnett A, Barach A, O'Neil $\mathrm{D}$, Tveit $\mathrm{O}$ et al. The influence of different sitting postures on head/neck posture and muscle activity. Man Ther. 2010 Feb;15(1):54-60. https://doi.org/10.1016/ j.math.2009.06.002 PMID: 19643658

10. Prins Y, Crous L, Louw QA. A systematic review of posture and psychosocial factors as contributors to upper quadrant musculoskeletal pain in children and adolescents. Physiother Theory Pract. 2008 JulAug;24(4):221-42. https://doi.org/10.1080/095939807 01704089 PMID: 18574749

11. 11. Cardon G, De Clercq D, De Bourdeaudhuij I, Breithecker D. Sitting habits in elementary schoolchildren: a traditional versus a "Moving school". Patient Educ Couns. 2004 Aug;54(2):133-42. https://doi.org/10.1016/S0738-3991(03)00215-5 PMID: 15288906

12. Mirbagheri SS, Mortazavi SS, Rahmani Rasa A, Hossein Alizadeh J. Relationship between spinal abnormalities and musculoskeletal pains in university students in Hamadan, Iran [Persian]. J ResRehabil Sci. 2013;9 (3):515-24.

13. Dianat I, Alipour A, Asgari Jafarabadi M. Risk factors for neck and shoulder pain among schoolchildren and adolescents. J Paediatr Child Health. 2018 Jan;54(1):20 7. https://doi.org/10.1111/jpc.13657 PMID:28782292

14. Dianat I, Alipour A, Asghari Jafarabadi M. Prevalence and risk factors of low back pain among school age children in Iran. Health Promot Perspect. 2017 Sep;7(4):223-9. https://doi.org/10.15171/hpp.2017.39 PMID:29085800 
15. Kuorinka I, Jonsson B, Kilbom A, Vinterberg H, BieringSørensen F, Andersson G et al. Standardised Nordic questionnaires for the analysis of musculoskeletal symptoms. Appl Ergon. 1987 Sep;18(3):233-7. https://doi.org/10.1016/0003-6870(87)90010-X PMID:15676628

16. Miri M. Hosseini2 M, Sharifzadeh3 G. Evaluation of ergonomic postures of hairdressers by REBA in Birjand [Persian]. Horizon Med Sci. 2008;14(2):39-44.

17. Ilbeigi S, Biglar A, Saghebjoo M, Farzaneh H. The investigation of relationship between work-related musculoskeletal disorders and level of physical activity and body posture of dentists in Mashhad city in 20122013 [Persian]. Journal of Torbat Heydariyeh University of Medical Sciences. 2014;2(4):31-7.

18. Afkhami ardakani R, Ganji B, Naser Meli MH. Study of relation between Violin playing history with pain prevalence and musculature abnormalities in violin players and presenting proposed protocol with the aim of correction. 10th International Congress on Sport Sciences; 2017 April 26-27: Tehran,Iran:2017.

19. Shojaatian M, Sadeghi H. Validation of ResearcherMade Ergonomic Assessment Test for Freestyle Wrestling Skills. J Ergon. 2016;4(2):26-36.

20. Brink Y, Louw Q, Grimmer K, Jordaan E. The spinal posture of computing adolescents in a real-life setting. BMC Musculoskelet Disord. 2014 Jun;15(1):212. https://doi.org/10.1186/1471-2474-15-212 PMID:24950887

21. Pillastrini P, Mugnai R, Bertozzi L, Costi S, Curti S, Guccione A et al. Effectiveness of an ergonomic intervention on work-related posture and low back pain in video display terminal operators: a 3 year cross-over trial. Appl Ergon. 2010 May;41(3):436-43. https://doi.org/10.1016/j.apergo.2009.09.008 PMID: 19853837
22. Hakala PT, Saarni LA, Punamäki RL, Wallenius MA, Nygård $\mathrm{CH}$, Rimpelä AH. Musculoskeletal symptoms and computer use among Finnish adolescents - pain intensity and inconvenience to everyday life: a crosssectional study. BMC Musculoskelet Disord. 2012 Mar;13(1):41. https://doi.org/10.1186/1471-2474-13-41 PMID:22439805

23. Geldhof E, De Clercq D, De Bourdeaudhuij I, Cardon G. Classroom postures of 8-12 year old children. Ergonomics. 2007 Oct;50(10):1571-81. https://doi.org/10.1080/00140130701587251 PMID: 17917898

24. Kuorinka I, Jonsson B, Kilbom A, Vinterberg H, BieringSørensen F, Andersson G et al. Standardised Nordic questionnaires for the analysis of musculoskeletal symptoms. Appl Ergon. 1987 Sep;18(3):233-7. https://doi.org/10.1016/0003-6870(87)90010-X PMID: 15676628

25. Papageorgiou AC, Croft PR, Thomas E, Ferry S, Jayson MI 4th, Silman AJ. Influence of previous pain experience on the episode incidence of low back pain: results from the South Manchester Back Pain Study. Pain. 1996 Aug;66(2-3):181-5. https://doi.org/10.1016/03043959(96)03022-9 PMID:8880839

26. Trevelyan FC, Legg SJ. The prevalence and characteristics of back pain among school children in New Zealand. Ergonomics. 2010 Dec;53(12):1455-60. https://doi.org/10.1080/00140139.2010.528455 PMID:21108082

27. Watson KD, Papageorgiou AC, Jones GT, Taylor S, Symmons DP, Silman AJ et al. Low back pain in schoolchildren: the role of mechanical and psychosocial factors. Arch Dis Child. 2003 Jan;88(1):12-7. https://doi.org/10.1136/adc.88.1.12 PMID:12495949

28. Prins Y, Crous L, Louw QA. A systematic review of posture and psychosocial factors as contributors to upper quadrant musculoskeletal pain in children and adolescents. Physiother Theory Pract. 2008 JulAug;24(4):221-42. https://doi.org/10.1080/095939807 01704089 PMID: $1857 \overline{74749}$ 